\title{
Evaluation of Animal Control Measures on Pet Demographics in Santa Clara County, California, 1993- 2006
}

A prospective cross-sectional study of 1000 households was implemented in 2005 to evaluate characteristics of the owned and unowned population of dogs and cats in Santa Clara County, California. The same population was previously studied 12 years earlier. During this time period, the county instituted in 1994 and then subsequently disestablished a municipal spay/neuter voucher program for cats. Dog intakes declined from 1992-2005, as they similarly did for an adjacent county (San Mateo). However, cat intakes declined significantly more in Santa Clara County than San Mateo, with an average annual decline of approximately 700 cats for the 12 year period. Time series analysis showed a greater than expected decline in the number of cats surrendered to shelters in Santa Clara County during the years the voucher program was in effect (1994-2005). The net savings to the county by reducing the number of cat shelter intakes was estimated at approximately $\$ 1.5$ million. 
4 Philip H. Kass, Karen L. Johnson and Hsin-Yi Weng

6 Affiliations: Department of Population Health and Reproduction, School of Veterinary

7 Medicine, University of California, Davis, CA (Kass), National Pet Alliance, San Jose, CA

8 (Johnson), and Department of Comparative Pathobiology, School of Veterinary Medicine, Purdue 9 University, West Lafayette, IN (Weng)

12 Requests for reprints should be sent to Philip H. Kass, Department of Population Health and 13 Reproduction, School of Veterinary Medicine, University of California, Davis, California, 95616.

14 Phone (530) 752-1358. E-mail: phkass@ucdavis.edu 
17 A prospective cross-sectional study of 1000 households was implemented in 2005 to evaluate 18 characteristics of the owned and unowned population of dogs and cats in Santa Clara County,

19 California. The same population was previously studied 12 years earlier. During this time

20 period, the county instituted in 1994 and then subsequently disestablished a municipal

21 spay/neuter voucher program for cats. Dog and cat intakes declined from 1992-2005, as they

22 similarly did for an adjacent county (San Mateo). Time series analysis showed a greater than

23 expected decline in the number of cats surrendered to shelters in Santa Clara County during the

24 years the voucher program was in effect (1994-2005). The net savings to the county by reducing

25 the number of cat shelter intakes was estimated at approximately \$1.5 million.

27 Keywords: animal euthanasia, animal population groups, epidemiology, population control, 28 population policy 
One of the greatest threats to the lives of cats and dogs in contemporary American society

34 does not come from infectious or noninfectious disease, but rather from the threat of being unowned or becoming unwanted and susceptible to abandonment or relinquishment to shelters.

36 Each year millions of healthy and potentially adoptable pets are euthanized for lack of ownership

37 or residence; the most palpable manifestation of this is witnessed at local municipal or private 38 animal shelters (Salman et al. 1998). The financial burden of managing this overabundance of 39 pets to communities across the United States is enormous and incalculable (Zanowski 2010). Scientific investigations into pet population dynamics have evolved from the purely 41 descriptive to the analytic, particularly with respect to studying determinants of relinquishment. 42 Many studies performed in the United States have sought to quantify characteristics of animals 43 as well as their owners that appear to be proscriptive for an impairment of the human-animal 44 bond . The cumulative effect of these studies has led to a better understanding of why 45 relinquishment occurs, but the enduring challenge remains how to use such information to 46 implement prevention and/or intervention strategies. A prototypical example of these strategies 47 is the establishment of community spay and neuter programs. Such programs can be sponsored 48 either by municipalities or humane organizations, both of which often jointly serve critical animal control needs in communities and frequently join together in collaboration to achieve 50 their mutual goals. Santa Clara County, California is an opportune place to study the results of intervention 52 strategies. As of 2005 the 1,291 square mile county contained 1.76 million people (in an 53 estimated 603,000 households, averaging 2.92 persons per household), with more than half $54(945,000)$ living in San Jose, and over 200,000 more living in the cities of Sunnyvale and Santa 55 Clara . The ethnic distribution was approximately 44\% Caucasian, 25\% Asian/Pacific Islander, 
24\% Hispanic/Latino, 3\% African-American, and 4\% other groups . Per capita annual growth

57 has been approximately $1.2 \%$; annual household growth has increased approximately $0.8 \%$ over

58 the past 15 years .

59 Two major animal shelters operate: the City of San Jose Animal Care \& Services

60 (SJACS) which opened in 2004, and the Humane Society of Silicon Valley (HSSV) facility in

61 Santa Clara, which accepted up to 25,000 animals per year. The latter predominantly provided

62 sheltering services until late 1992, when for financial reasons the County ceased field services

63 for cats, only accepting those owner-reliquished. The HSSV recommenced services 14 months

64 later for most of the County.

65 The number of cats entering the HSSV climbed approximately 25\% (from 20,000 to

6625,000 cats) from 1983 to 1990, and remained close to its high until Santa Clara County field

67 services ended in 1992; in 1993 the total number of incoming live cats returned to 20,000 .

68 Approximately $60 \%$ of incoming animals to HSSV arrived through field services. Upon

69 resumption of these services in 1994, San Jose instituted a free spay/neuter voucher program to

70 reduce its number of stray cats, and initiated one for dogs in 1995. These programs ceased in

712003 in anticipation of the SJACS opening, but temporarily resumed in 2005 until the latter

72 opened its own low-cost spay/neuter clinic in 2006. Santa Clara County also instituted a

73 low-cost spay/neuter program in 1998 with almost \$50,000 in annual funding.

74 A local non-profit organization of cat and dog owners and fanciers ${ }^{\mathrm{a}}$ commissioned a

75 survey of Santa Clara County residents in 1993. The purpose of this survey was estimate the

76 number of owned and unowned cats and dogs in the county. Investigators interviewed people by

77 telephone from 1,031 households throughout all parts of the County except the city of Palo Alto

78 (whose small shelter declined to provide intake statistics), and determined that 51\% of 
79 households did not own pets, 19\% owned only cats, $19 \%$ owned only dogs, and $11 \%$ owned

80 both cats and dogs. Households that owned cats and dogs had an average of 1.7 cats and of 1.3

81 dogs, respectively. Ten percent of all households (48\% of which did not own pets) also cared for

82 an average of 3.4 stray cats. Strays, sometimes referred to as community cats, are free-roaming,

83 unowned, or feral; the latter do not allow human touch. These figures led investigators to

84 estimate that in 1993 the number of owned cats and dogs in the county was approximately

85247,000 and 195,000, respectively (Cat Fanciers Almanac 1994). Of particular importance was

86 the projection that the County had approximately 169,000 unowned but fed cats ( $41 \%$ of all cats

87 in the county), a figure that does not account for unowned but unfed and feral cats.

88 The purpose of the current study, conducted in 2005, was to revisit the population of cats

89 and dogs in Santa Clara County 12 years following the earlier study, and to correlate pet

90 population changes with the institution or disestablishment of animal population control

91 programs, including vouchers, field services, and low-cost spay and neuter facilities. The

92 hypothesis was that these programs would be associated with a reduction in the pet populations

93 in Santa Clara County that differed from that of an adjacent comparison county, with resultant

94 cost savings to the county.

96 Materials and Methods

97 Study population

98 The same private survey firm used in 1993 was commissioned to conduct a similar

99 random telephone survey of 1,000 households throughout Santa Clara County except Palo Alto

100 (which has its own small shelter and did not participate in 1993). An equal probability of

101 selection method (EPSEM) phone list of residential landline telephone numbers for the survey 
102 was purchased from a private company. ${ }^{1}$ Three attempts were made at each number over

103 successive nights. Over 7,000 calls (including disconnected lines, no answers, refusals) were

104 attempted to reach 1000 respondents. People who agreed to be questioned were asked whether

105 or not they owned dogs or cats, fed stray dogs or cats, whether or not the animals had been

106 altered, if they had reproduced, if cats had been declawed, how they obtained their pets, whether

107 or not cats were allowed outside, purebred status, city of residence, and residence type. Data was

108 initially recorded on written interview forms, and manually entered into a Microsoft Excel 2007

109 (Microsoft Corporation, Redmond, WA) spreadsheet for statistical analysis.

110 Animal shelter entry information was provided by Santa Clara County Animal Control,

111 Humane Society of Silicon Valley, San Jose Animal Care and Services, and for comparative

112 purposes the Peninsula Humane Society and SPCA in neighboring San Mateo County and Los

113 Angeles County Animal Control. Spay/neuter voucher program information, costs and statistics

114 were obtained from the City of San Jose, and County of Santa Clara. San Mateo County was

115 chosen for comparative purposes, as it most closely resembled Santa Clara County, as opposed to

116 the other four more rural surrounding counties.

118 Statistical analysis

119 The 1982-1993 Santa Clara County shelter intake records (from before the launch of the

120 spay/neuter voucher program) were used for projecting the expected numbers of shelter intakes

121 from 1994 to 2005. US Census data was used to determine the number of county households,

122 which was used with survey-derived estimates of the average number of dogs and cats per

123 household and proportion of households that owned dogs and cats to estimate the number of

124 owned dogs and cats in the county, and with survey-derived estimates of the percentage of 
125 households feeding stray dogs and the average number of unowned but fed dogs and cats per

126 household to estimate the number of stray dogs and cats in the county.

127 Data from the survey was initially described using proportions. Pearson's chi-square test

128 was used to compare proportions; $p$-values $<0.05$ were considered statistically significant. The

129 observed numbers of shelter intakes between 1994 and 2005, during which the spay/neuter

130 program was in place, were compared with projected numbers based on varying the proportion

131 of cats in the voucher program that were owned versus unowned to assess the program's effect

132 (i.e., change in numbers of shelter intakes). Autoregressive integrated moving average (ARIMA

133 ( $\mathrm{p}, \mathrm{q}, \mathrm{d}$, where $\mathrm{p}=$ order of autoregression, $\mathrm{q}=$ order of moving averages, and $\mathrm{d}=$ order of

134 differencing)) models were fit to the data before the launch of the spay/neuter voucher program

135 (1982 to 1993). Autocorrelation function (ACF) and partial autocorrelation function (PACF)

136 plots were used to select the best-fit ARIMA models and to evaluate the model fit. The selected

137 ARIMA models were then used to estimate and project the trend in number of shelter intakes

138 after the implementation of spay/neuter program (1994 to 2005) with corresponding 95\%

139 confidence limits of the ARIMA projections. In addition, we constructed a stochastic model to

140 estimate the number of additional cats that would have been born and taken into the shelters

141 between 1994 and 2005 had the spay/neuter program never been implemented. The key

142 parameters, their corresponding probability distributions for owned and unowned cats, and the

143 data sources are listed in Table 1. This model was also used for benefit-cost analysis of the

144 voucher program. The software program @Risk (version 5.0.0, Palisade Corp., Ithaca, New

145 York) was used for the simulation, using Latin Hypercube sampling and Mersenne Twister

146 generator with a fixed initial seed of 12345 for 10,000 iterations. Median and the 5th and 95th

147 percentiles were reported. 


\section{Results}

150

151

152

153

154

155

156

157

158

159

160

161

162

163

164

165

166

167

168

169

170

Dog survey results

Twenty nine percent of responding county households reported that they owned dogs (unchanged from 1993); the average household owned 1.9 dogs, representing an increase from

1.3 dogs in 1993. Using US census data led to an estimate of 332,000 owned dogs in Santa Clara County (assuming Palo Alto has the same ownership frequency). Registered and unregistered purebred dogs were $33 \%$ and $18 \%$ (total $=51 \%$ ) of the dog population, respectively; the remainder (49\%) of dogs was either mixed or unknown breeds. Dogs were acquired from a variety of sources; the most common were friends or relatives (30\%), breeders (25\%), public or private animal shelter (15\%), with the remainder (less than 10\% each) coming from a breed rescue group, a newspaper advertisement, found as stray, being born at home, acquired from a pet store, and rare other sources (Fig.1).

Seventy five percent (75\%) of owners reported surgically sterilizing their dogs. Among those that declined to alter them, $28 \%$ of owners said this was a deliberate decision, and none claimed that cost was a justification for not sterilizing. Thirty three percent (33\%) of the unaltered dogs were intended for breeding purposes, and 17\% were puppies too young for surgery. Of the 99 unaltered dogs, 70 (70.7\%) were male and 29 (29.3\%) were female. Twenty one households (2\%) in the survey acknowledged feeding dogs they did not own, with an average of 2.3 dogs per feeding household. An examination of zip codes indicated that the majority of these dogs were found in the downtown and north and east sides of the city of San Jose. With some exceptions, these areas are in the lower socio-economic range of households in San Jose. Using US census data, this leads to an estimate of approximately 15,650 
171 transiently or permanently stray dogs throughout the county, or $4.7 \%$ of the county's dog

172 population.

173

174 Cat survey results

175 Twenty five percent of households reported owning cats, representing a decrease from

$17630 \%$ in $1993(p=0.013)$. With an average of 1.7 owned cats per household (a figure unchanged

177 since 1993), the county’s owned cat population was estimated at 256,000 cats. Most cats (85\%)

178 were characterized as domestic varieties; only 3\% were claimed to be registered pedigree (a

179 figure unchanged since 1993), while others were described as unregistered pedigreed or

180 unknown breed. The percentage of cats kept strictly indoors rose from 33\% in 1993 to $49 \%$ in

$1812005(p<0.001)$; only $8 \%$ were currently described as strictly outdoors, down from $14 \%$ in 1993

$182(p<0.001)$.

183 The most common source of owned cats was from a friend or relative (42\% in 2005

184 versus 33\% in 1993), followed by being found as a free-roaming homeless cat (20\% in 2005

185 versus 32\% in 1993), a public or private animal shelter (16\% in 2005 versus $12 \%$ in 1993), a

186 breed rescue group ( $9 \%$ in 2005 versus $2 \%$ in 1993), a breeder ( $4 \%$ in both years), an ad in a

187 newspaper or adopted or purchased in a pet store ( $2 \%$ in 2005 versus $6 \%$ in 1993), a negligible

188 percentage born at home ( $<1 \%$ in 2005 versus $6 \%$ in 1993), and the remainder coming from

189 various minor or unknown sources. The $p$-value comparing the source distribution of owned cats

190 between 2005 and 1993 was $<0.001$.

191 In 2005 most cat owners (92.8\%) had their cats surgically sterilized, compared to 86\% in

$1921993(p<0.001)$. Within the $7.2 \%$ of cats not spayed or neutered, $48 \%$ had owners that

193 deliberately did not want their cats to be sterilized, 13\% had owners who wanted to retain the cat 
194 for breeding, $13 \%$ were kittens, $13 \%$ had owners claiming that the costs were prohibitive, and the

195 remainder gave two or more reasons (the most common of which was lack of time to transport

196 the cat for surgery). Thus, only approximately $6 \%$ of owned cats were sexually mature and

197 capable of breeding, approximately half of which were female. However, less than one-half of

$1981 \%$ of owners of sterilized female cats allowed their cats to have a litter prior to sterilization.

199 The rate of reproduction of owned cats in Santa Clara County was 89 cats per 1000

200 households, in contrast to the higher rate of 112 kittens per 1000 households in the 1996 National

201 Council on Pet Population Study and Policy (Salman et al., 1998). This may be attributable to

202 the high proportion of altered cats in the county (93\%) relative to the comparable 1993 figure

203 and the 2005 national average of 86\%. In addition, while in 1993 16\% of owned cats had a litter

204 prior to altering, in the current study this figure was less than one-half of $1 \%$. While it was

205 beyond the scope of this study to determine the reasons for this change in attitude, it is likely that

206 greater awareness prompted by considerable multimedia public education about the

207 county-sponsored voucher program instituted in 1993 bore at least some responsibility.

208 When owners were asked about whether their cats were declawed, 8\% stated that they

209 were, but $29 \%$ of them obtained the cat in that condition. The most common reason given by

210 owners (84\%) for declawing was to protect furniture. Owners not electing to declaw their cats

211 protected their furniture through a variety of means, including having scratching posts and mats,

212 using a spray bottle, clipping the claws, applying double-sided tape, and making loud deterrent

213 noises.

214 Many individuals fed stray cats: 7\% of household respondents admitted to feeding an

215 average of 3.2 cats, a decrease from $10 \%$ with an average of 3.4 cats in 1993. Relying on U.S.

216 census data, the estimated fed stray cat population is therefore approximately 135,000 cats, or 
217 approximately 35\% of the total owned and fed free-roaming/unowned cat population in the

218 county (391,000 cats, which represents a drop from 416,000 in 1993). Only 5.5\% of these cats

219 were either trapped or taken to be surgically sterilized by their people feeding them. Fifty six

220 percent of the cats were fed daily, while the remaining cats were fed from once every other day

221 to only occasionally. The cats were most commonly fed on the doorstep of a person's home

222 (62\%), followed by an office (15\%), a park (12\%), and a shopping center $(<1 \%)$. Fed stray cats

223 were either alone or belonged to colonies ranging in size from 2 to 25 cats. Two-thirds of the fed

224 stray cats were too wild to be picked up and were defined as feral; the remaining third were

225 classified as unowned (although some of these may have had owners unknown to the survey

226 respondent). Forty seven percent of the female stray cats were known to have had at least one

227 litter, which is probably a conservative estimate. Over half of the known litters were allowed to

228 remain free and disperse into their neighborhoods. Of the remaining kittens, half were kept by

229 the feeder, while the others were given away or taken to an animal shelter. Of the females who

230 had litters, 58\% were not trapped or taken to a veterinarian after having a litter, remaining free to

231 potentially breed again.

232

233

Population changes at Santa Clara County Animal Shelters

234

Changes in dog shelter intakes for Santa Clara County (and the Peninsula Humane

235 Society and SPCA shelter in adjacent San Mateo County for comparison) are shown in Fig. 2.

236 Dog intakes declined 13,643 to 8,441 (38.1\%) from 1992-2005 in Santa Clara County. An

237 external explanation for the observed trend is supported by the findings in adjacent San Mateo

238 County, where dog intakes declined by a similar 35.7\% between 1990 and 2004. These

239 proportions were not significantly different $(p=0.11)$. 
A substantially different picture emerged when examining changes in cat shelter intakes

241 in Santa Clara and San Mateo Counties (Figs. 3 and 4). Intakes in Santa Clara County dropped

242 22,473 to 16,369 (27.2\%) from 1993 to 2004 and 22,473 to 16,807 (25.2\%) from 1993 to 2005,

243 compared to a drop of 8,252 to 6,078 (26.3\%) in San Mateo County from 1993 to 2004.

244 Although the two 1993 to 2004 proportions were similar $(p=0.16)$, there was an overall decline

245 in annual intakes in Santa Clara County of 6,104 cats to 2004 (509 cats per year) for the 12 year

246 period, compared to 2,174 cats in the same 12 year period for San Mateo County (181 cats per

247 year). The absolute changes are economically more germane to counties with respect to shelter

248 expenses because expenditures are based on the per diem cost of maintaining individual cats.

249 The results of the ARIMA $(1,0,1)$ projections indicated a higher-than-expected cat intake to

250 shelters in Santa Clara County during the years when the voucher program was in effect, i.e.,

251 1994-2005 (Fig.5). The ARIMA (1,0,1) projections further showed that the observed numbers of

252 cats brought in by the field service did not substantially differ from the expected numbers during

253 the same time period (Fig.6).

254 Information provided by the HSSV shelter indicated that the majority of cats entering the

255 shelter were unweaned kittens and feral cats. From 2000 to 2004, the HSSV euthanized 53,419

256 cats deemed unadoptable: 14,406 were too young (under four weeks of age), 7,912 were

257 unsociable, and 7,595 were feral.

258 Under the voucher program, 20,419 cats were surgically sterilized from 1994-2001 and

259 an additional 6,231 cats were sterilized from 2001-2003. While the program was initiated at the

260 end of 1994, public interest did not start until mid-1995, when a local television station and

261 newspaper ran a story about it. 
263 over time were instituted. Veterinarians were reimbursed at a set fee of $\$ 25$ female and $\$ 15$

264 male. Pregnancies could add to the veterinarian reimbursement up to $\$ 50$, and anatomical issues

265 adjusted the price to as high as $\$ 150$. In 1996 modifications included requiring a \$5 co-pay, and 266 a requirement that cat owners obtain a \$5 license and rabies inoculation. While these changes

267 increased the veterinarian reimbursement, they also created a negative effect on the program, as

268 voucher requests declined from 5,600 in the first 16 months of the program to only 2,800 for the 269 year following the changes.

270 The San Jose voucher program ended in 2003, but the county program continued.

271 Utilizing assumptions in Table 1, if no voucher program had been initiated, the same cats

272 enrolled in the voucher program (assuming that 65\% were owned, based on the 2005 survey

273 results) would have produced approximately 312,000 kittens between 1994 and 2005, and

274 approximately 8,600 additional cats would have entered (6,200 surrendered and 2,500 brought in

275 by the field service) the shelters in Santa Clara County. This would have incurred an additional

276 cost of approximately $\$ 2.15$ million, with the HSSV charge to cities for stray cat services under

277 their contract cost of $\$ 250$ per cat. If the cost per cat for spay/neuter surgery in 2001-2002

278 (\$23.21 average for all surgeries) can be assumed to be constant from 1994-2005, then the

279 expected cost of the HSSV voucher program was approximately $\$ 620,000$. Thus, the net gain of 280 the program from reducing the number of cat shelter intakes was approximately $\$ 1.53$ million.

281 Not counted would be the added burden of approximately 44,000 cats to the stray population in 282 the county.

283 The proportion of feral cats actually altered in the program considerably fluctuated: from $28477 \%$ in 2006 to $82 \%$ in 2007 to $48 \%$ in 2008 (the latter data is from San Jose only). Table 2 
285

286

287

288

289

290

\section{Discussion \\ Discussion}

292

293

294

295

296

297

298

299

300

301

302

303

304

305

306

contains projections of how county cat and shelter populations would be expected to change in the absence of the voucher program under different owned versus feral cat ratios. Under all plausible scenarios, ranging from $20 \%$ to $80 \%$ of the altered cats being feral, the costs to the shelters would have likely exceeded \$2 million over the 12-year life of the program, and at the higher proportion of feral cats the costs would have likely exceeded \$6 million.

This study documents the positive impacts publically subsidized low-cost spay and neuter programs can have that often go unmet in communities: pet population control, leading to the prevention of the proliferation of feral dog and cat populations, slowing the flow of animals into shelters both voluntarily and through field services, and reduction in the incidence of humane destruction of animals. But they also extend to other issues of economic importance to communities; namely, reduction in capital and ongoing animal control expenditures that come under a municipality's jurisdiction. In contrast, the implication of cessation of such programs can be seen in Figures 2 and 3 when the decline in shelter admissions of dogs and cats became attenuated. The problem could be exacerbated over time as the human (and hence pet-owning) population increases.

$$
\text { The finding that there were over 15,000 dogs (4.7\% of the county's dog population) }
$$

estimated to be transiently or permanently stray throughout the county is troubling from societal and public health standpoints. The absence of a domestic environment can lead stray dogs, which are by nature gregarious, to form packs that can become aggressive and endanger other animals and even humans. The origin of such a large number of dogs is worthy of further 
307 research, as this study did not explore whether these were free-roaming dogs or those kept in

308 temporary foster or rescue care.

309 Specific breed information was not available for dogs in Santa Clara County animal

310 shelters. Respondents claimed 51\% of their dogs were registered and unregistered purebred dogs.

311 This stands in contrast to a 1996 national survey that found 30\% of dogs relinquished to shelters

312 were purebred (Salman et al. 1998), and the Humane Society of the United States estimates that

$31325-30 \%$ of shelter dogs are purebred (The Humane Society of the United States 2011).

314 Nationally, purebred dogs are substantially less likely to be relinquished to animal shelters than

315 dogs of mixed breed (Salman et al. 1998).

316 The dogs with greatest likelihood of successful adoption from county animal shelters are

317 puppies (Lepper, Kass \& Hart 2002). By the time dogs reach the age of one year, though, their

318 risk of unsuccessful adoption following relinquishment rises considerably; again, particularly

319 true in pit bull-like breeds (Lepper, Kass \& Hart 2002). Aggressive dog behavior is a major

320 reason dogs are euthanized at the county shelters (Kass et al. 2001). To reduce dog intakes,

321 municipalities should consider how the establishment of free or low cost puppy training

322 programs (potentially mandatory for shelter adoptions) might impact shelter populations. A

323 collaborative effort among multiple community agencies, including animal control, non-profits,

324 and local pet industry businesses should be explored.

325 Another important finding is the enumeration of the substantial unowned cat population

326 in Santa Clara County, two-thirds of which are feral. Also notable is that the majority of

327 unowned cats entering the animal shelters in the study were arguably unsuitable for adoption,

328 with over $50 \%$ being feral or unweaned kittens. Such cats are often quickly euthanized.

329 Preventing such input defies simplistic solutions, because although 93\% of cat owners were 
willing to have their own pets surgically sterilized, it is unrealistic to expect the $7 \%$ of the

331 population that feeds an average of 3 stray cats to assume the hundreds of dollars necessary to

332 surgically alter these cats.

333 Conversely, the cost of not altering the cats is to add 3.5 kittens per year for each stray

334 female, which at the cost to a shelter of approximately \$250 per cat would cost a shelter almost

$335 \$ 900$ in husbandry expenses for those 3.5 kittens; were they not sheltered, the kittens would be

336 expected to have $75 \%$ mortality (Table 1 ). The underscores why low-cost spay and neuter

337 programs directed to reducing the un-owned and feral cat populations continue to be integral to

338 not only reducing cat mortality at the shelters, but also to managing the cost to the various

339 municipalities to handle and house the stray cats. Santa Clara County’s contribution of $\$ 45$ to

340 alter a stray cat under its separate feral spay/neuter program created an immediate savings of

341 over $\$ 200$ for just the first litter that permanently results in non-reproducing cats. The county

342 program also subsidized shots, and for a time, FELV testing. The earlier such cats can be

343 sterilized, the greater the potential savings to municipalities. The savings would be expected to

344 grow over additional years. Moreover, under all plausible scenarios shown in Table 2 the

345 voucher program would have resulted in a net savings in expenditure.

346 If stray cat-feeding citizens can be convinced through public education to avail

347 themselves of population control options by making them more affordable and they are provided

348 with instructions and resources as to how to accomplish this activity, the savings in costs and

349 lives will be substantial. This study shows approximately 93\% of county residents did not make

350 an effort to sterilize unowned cats. Only 5.5\% of the unowned but fed cats were surgically

351 sterilized. Efforts should be focused on removing barriers and finding ways to encourage those

352 who feed free-roaming cats to take this important step. Because the study shows that $62 \%$ of 
353 unowned but fed cats are fed in people’s yards, efforts should be intensified to sterilize cats

354 living in close proximity to homes, rather than less accessible colonies.

355 This study's limitations include the assumption that the participating individuals are

356 representative of the county's population. Interviews were conducted via telephone, with the

357 non-telephone-owning segment of the county excluded by design, and to the extent that this

358 subgroup differs in their pet ownership and practices the findings cannot be generalized to them.

359 However, calls were made to each zip code in the county, and the number of respondents

360 completing the survey in each zip code, were proportionate to their share of the county

361 population. Although the finding that shelter intake declined in association with the inception of

362 the voucher program, the presence of extraneous (confounding) factors associated both with time

363 and shelter intake cannot be ruled out, including migration into and out of the county (although

364 the human population actually increased during the study period). At the time of the study, two

365 additional smaller shelters existed in the county: a county facility in San Martin, which served

366 the $5 \%$ of the population not living within cities, and a city facility in Palo Alto, which only

367 served Palo Alto residents; these shelters were not expected to have any meaningful impact on

368 intake changes in the shelters in this study.

369 In conclusion, this study demonstrates the financial and societal value of instituting a

370 low-cost voucher program on a county-wide scale. Although the parameters utilized in the

371 projections and models in this research (e.g., fecundity and mortality) will vary, perhaps

372 substantially, from county to county, they are realistic and based on published observations. It is

373 therefore likely that the qualitative - if not the precise quantitative -- benefits of the voucher

374 program in Santa Clara County will be of significance if incepted elsewhere. 


\section{Acknowledgements}

376

377 We are grateful to Beth Ward and Chris Benninger at the Humane Society of Silicon Valley, Greg

378 VanWassenhove at County of Santa Clara, and Jon Cicirelli at the City of San Jose for providing 379 annual shelter statistics.

380

381 


\section{References}

383

384 Cat Fanciers Almanac. (1994). National Pet Alliance’s Survey Report on Santa Clara County’s 385 Pet Population. San Jose, CA: National Pet Alliance.

386 Humane Society of the United States. (2011). Adopting from an Animal Shelter or Rescue $387 \quad$ Group. Available at http://www.humanesociety.org/issues/adopt/tips/adopting from shelter rescue.html (accessed 12 November 2012).

390 Jemmett JE, Evans JM. 1977. A survey of sexual behavior and reproduction in female cats. Journal of Small Animal Practice 18:31-37.

Kass PH, New JC, Scarlett JM, Salman MD. 2001. Understanding Animal Companion Surplus in the United States: Relinquishment of Nonadoptables to Animal Shelters for Euthanasia. Journal of Applied Animal Welfare Science 4:237-248.

Lepper M, Kass PH, Hart LA. 2002. Prediction of adoption versus euthanasia among dogs and cats in a California animal Shelter. Journal of Applied Animal Welfare Science 5:29-42.

Levy JK, Gale DW, Gale LA. 2003. Evaluation of the effect of a long-term trap-neuter-return and and death rate estimates of cats and dogs in U.S. households and related factors. Journal of Applied Animal Welfare Science 7:229-241. 
403 New JG Jr, Salman MD, Scarlett JM, Kass PH, Vaughn JA, Scherr S, Kelch WJ. 1999. Moving:

404 Characteristics of Dogs and Cats and Those Relinquishing Them to 12 U.S. Animal

405 Shelters. Journal of Applied Animal Welfare Science 2:83-96.

406 Nutter FB, Levine JF, Stoskopf MK. 2004. Reproductive capacity of free-roaming domestic cats

407 and kitten survival rate. [Research Support, Non-U.S. Gov't]. Journal of the American

408 Veterinary Medical Assocication 225:1399-1402.

409 Patronek GJ, Glickman LT, Beck AM, McCabe GP, Ecker C. 1996. Risk factors for

410 relinquishment of dogs to an animal shelter. Journal of the American Veterinary Medical

$411 \quad$ Association 209:572-581.

412 Patronek GJ, Glickman LT, Beck AM, McCabe GP, Ecker C. 1996. Risk factors for

413 relinquishment of cats to an animal shelter. Journal of the American Veterinary Medical

$414 \quad$ Association 209:582-588.

415 Pedersen NC. 1991. Feline husbandry: Diseases and management in the multiple-cat

416 environment. Goleta, CA: American Veterinary Publications.

417 Salman MD, New JG Jr, Scarlett JM, Kass PH, Ruch-Gallie R, Hetts S. 1998. Human and

418 Animal Factors Related to Relinquishment of Dogs and Cats in 12 Selected Animal

419 Shelters in the United States. Journal of Applied Animal Welfare Science 1:207-226.

420 Scarlett JM, Salman MD, New JG Jr, Kass PH. 1999. Reasons for Relinquishment of Companion

421 Animals in U.S. Animal Shelters: Selected Health and Personal Issues. Journal of

$422 \quad$ Applied Animal Welfare Science 2:41-57.

423 Scott KC, Levy JK, Crawford PC. 2002. Characteristics of free-roaming cats evaluated in a

424 trap-neuter-return program. Journal of the American Veterinary Medical Association

$425 \quad 221: 1136-1138$. 
426 State of California. (2009a). Table B-3: Total population of California counties as of July 1.

427 Available at http://www.dof.ca.gov/HTML/FS DATA/STAT-ABS/Toc xls.htm (accessed

42812 November 2012).

429 State of California. (2009b). Table B-5: Population and percent distribution by race and Hispanic

430 origin, California, Census 2000. Available at

431 http://www.dof.ca.gov/HTML/FS DATA/STAT-ABS/Toc xls.htm (accessed 12

$432 \quad$ November 2012).

433 U.S. Census Bureau. (2012). State \& County QuickFacts. Santa Clara County, California.

434 Available at http://quickfacts.census.gov/qfd/states/06/06085.html (accesssed 12

$435 \quad$ November 2012).

436 Zanowski GN. 2010. The true costs of euthanasia in animal shelters: a comprehensive

437

examination. International Journal of Liability and Scientific Enquiry 3:291-319. 


\section{Footnotes}

440

441

${ }^{1}$ Scientific Telephone Samples, Foothill Ranch, California 


\section{Table $\mathbf{1}_{\text {(on next page) }}$}

Information used in modeling cat population dynamics from 1994 to 2005 if no spay/neuter voucher program had been initiated in Santa Clara County, California. 


\begin{tabular}{|c|c|c|c|}
\hline Parameter & Owned cats & Unowned cats & References \\
\hline Kittens/litter & 4.25 & 3.6 & $\begin{array}{l}\text { Pedersen, 1991; Scott et al., } \\
2002\end{array}$ \\
\hline Kitten mortality rate (\%) & 30 & 75 & $\begin{array}{l}\text { Jemmett and Evans, 1977; } \\
\text { Nutter et al., 2004; Scott et al., } \\
1978\end{array}$ \\
\hline Life expectancy (years) & 12 & 4.7 & $\begin{array}{l}\text { Levy et al., 2003; New et al. } \\
2004\end{array}$ \\
\hline Litters per female per year & 2.1 & 1.4 & $\begin{array}{l}\text { Pedersen, 1991, Nutter et al., } \\
\text { 2004; Levy et al., 2003; Scott et } \\
\text { al., } 2002\end{array}$ \\
\hline Percent female & 55 & 45 & Levy et al., 2003 \\
\hline Sexually intact (\%) & 14 & 94.5 & 1993 and 2005 surveys \\
\hline Surrendered to shelter (\%) & 3.0 & 7.3 & $\begin{array}{l}1993 \text { survey and shelter } \\
\text { statistics }\end{array}$ \\
\hline
\end{tabular}




\section{Table $2_{\text {(on next page) }}$}

Projected impact of hypothetical absence of the 12 year spay/neuter program on cat populations, shelter intake, and municipal cost in Santa Clara County.

Median and the $5^{\text {th }}$ and $95^{\text {th }}$ percentiles (in parentheses) are reported $(x \$ 1,000)$. 


\begin{tabular}{ccccccc}
\hline $\begin{array}{c}\text { Percentage of } \\
\text { surgeries } \\
\text { performed on } \\
\text { owned cats }\end{array}$ & $\begin{array}{c}\text { Additional } \\
\text { number of } \\
\text { owned cats }\end{array}$ & $\begin{array}{c}\text { Additional } \\
\text { number of } \\
\text { stray cats }\end{array}$ & $\begin{array}{c}\text { Cats } \\
\text { voluntarily } \\
\text { surrendered } \\
\text { to shelter }\end{array}$ & $\begin{array}{c}\text { Cats } \\
\text { brought in } \\
\text { by field } \\
\text { service }\end{array}$ & $\begin{array}{c}\text { Total } \\
\text { additional } \\
\text { shelter } \\
\text { cat intake }\end{array}$ & $\begin{array}{c}\text { Cost to shelter } \\
\text { for additional } \\
\text { surrendered } \\
\text { and stray cats }\end{array}$ \\
\hline 20 & 193 & 265 & 6 & 20 & 25 & $\$ 6,333$ \\
& $(110,388)$ & $(131,593)$ & $(3,12)$ & $(10,44)$ & $(13,55)$ & $(3,242,13,817)$ \\
30 & 226 & 181 & 7 & 13 & 20 & $\$ 5,034$ \\
& $(140,412)$ & $(98,367)$ & $(4,13)$ & $(7,27)$ & $(11,40)$ & $(2,867,9,893)$ \\
40 & 239 & 124 & 7 & 9 & 16 & $\$ 4,078$ \\
& $(159,398)$ & $(73,226)$ & $(5,12)$ & $(5,17)$ & $(10,28)$ & $(2,549,7,089)$ \\
50 & 242 & 84 & 7 & 6 & 13 & $\$ 3,351$ \\
& $(173,368)$ & $(54,138)$ & $(5,11)$ & $(4,10)$ & $(9,21)$ & $(2,282,5,291)$ \\
60 & 241 & 55 & 7 & 4 & 11 & $\$ 2,823$ \\
& $(180,342)$ & $(38,85)$ & $(5,10)$ & $(3,6)$ & $(8,17)$ & $(2,035,4,135)$ \\
70 & 236 & 35 & 7 & 3 & 10 & $\$ 2,411$ \\
& $(182,319)$ & $(25,50)$ & $(5,10)$ & $(2,4)$ & $(7,13)$ & $(1,814,3,324)$ \\
& 231 & 20 & 7 & 1 & 8 & $\$ 2,099$ \\
& $(182,303)$ & $(15,27)$ & $(5,9)$ & $(1,2)$ & $(6,11)$ & $(1,625,2,792)$ \\
\hline
\end{tabular}




\section{Figure 1}

Source of acquisition of dogs from Santa Clara County survey, 2005.

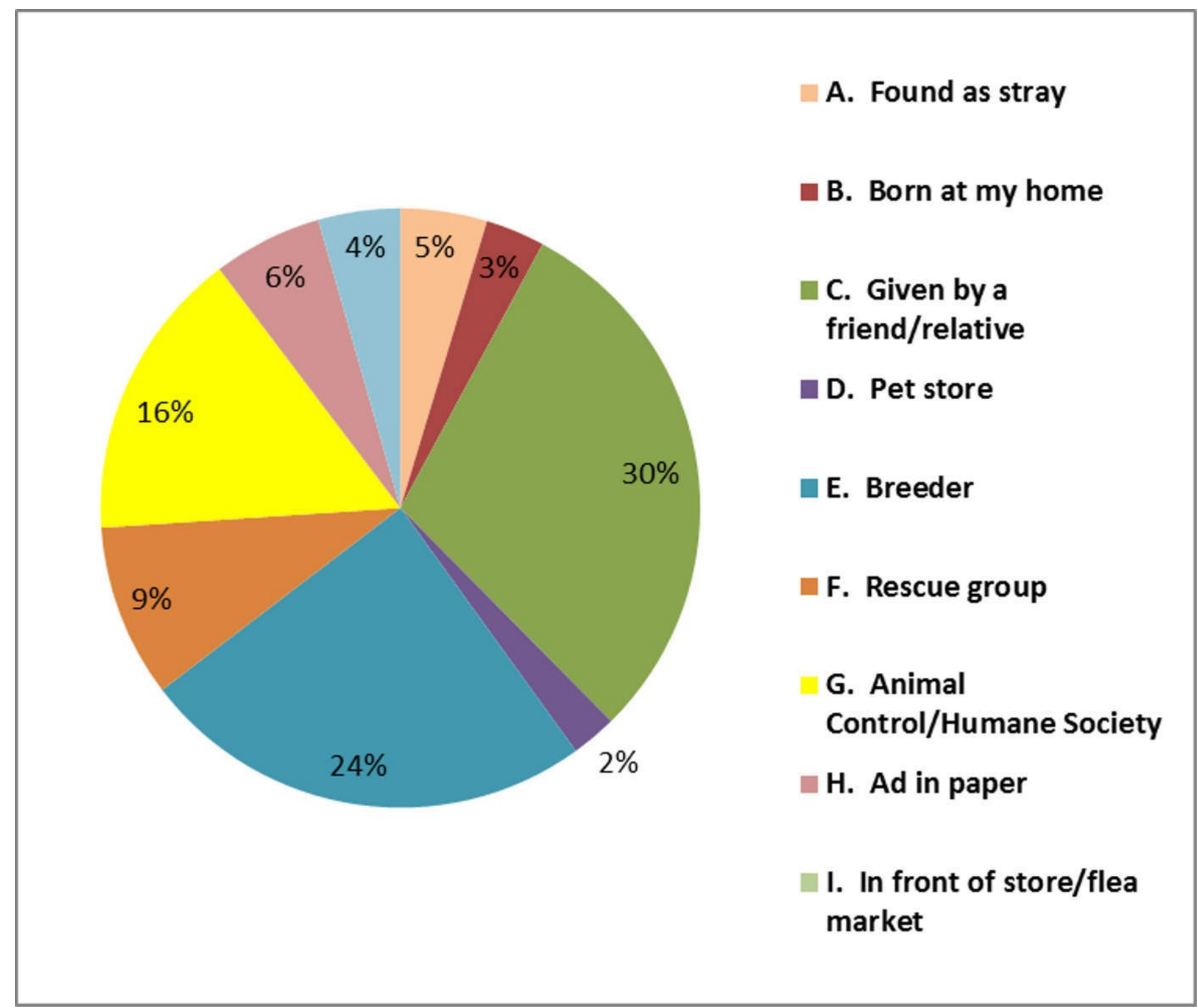




\section{Figure 2}

Regression analysis of intake of dogs at shelters in Santa Clara County $(r=0.95)$ and San Mateo County $(r=0.97)$ over time $(1990-2005)$.

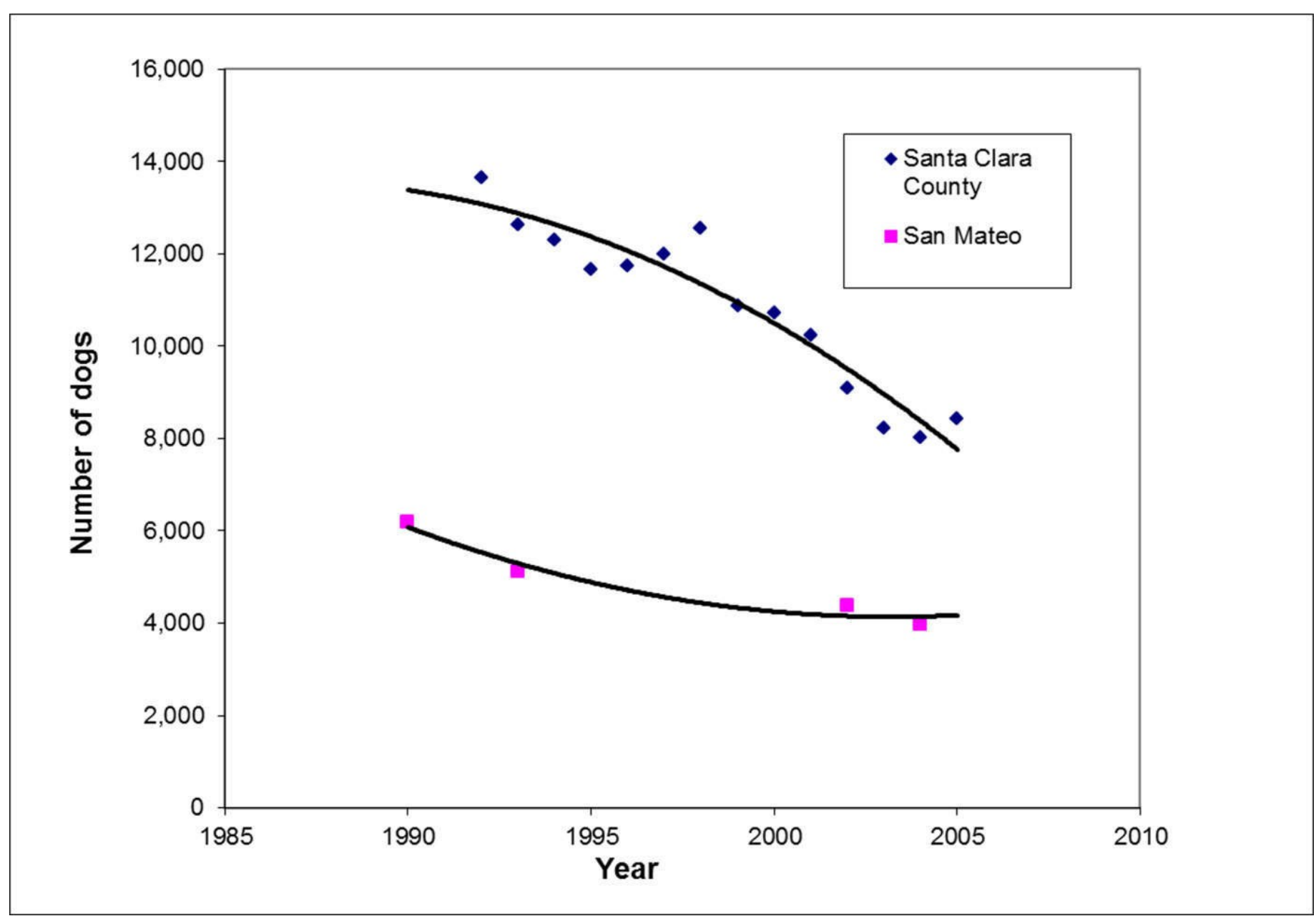




\section{Figure 3}

Secular changes in cat intakes in Santa Clara County, 1982 - 2007, indexed by historically relevant events.

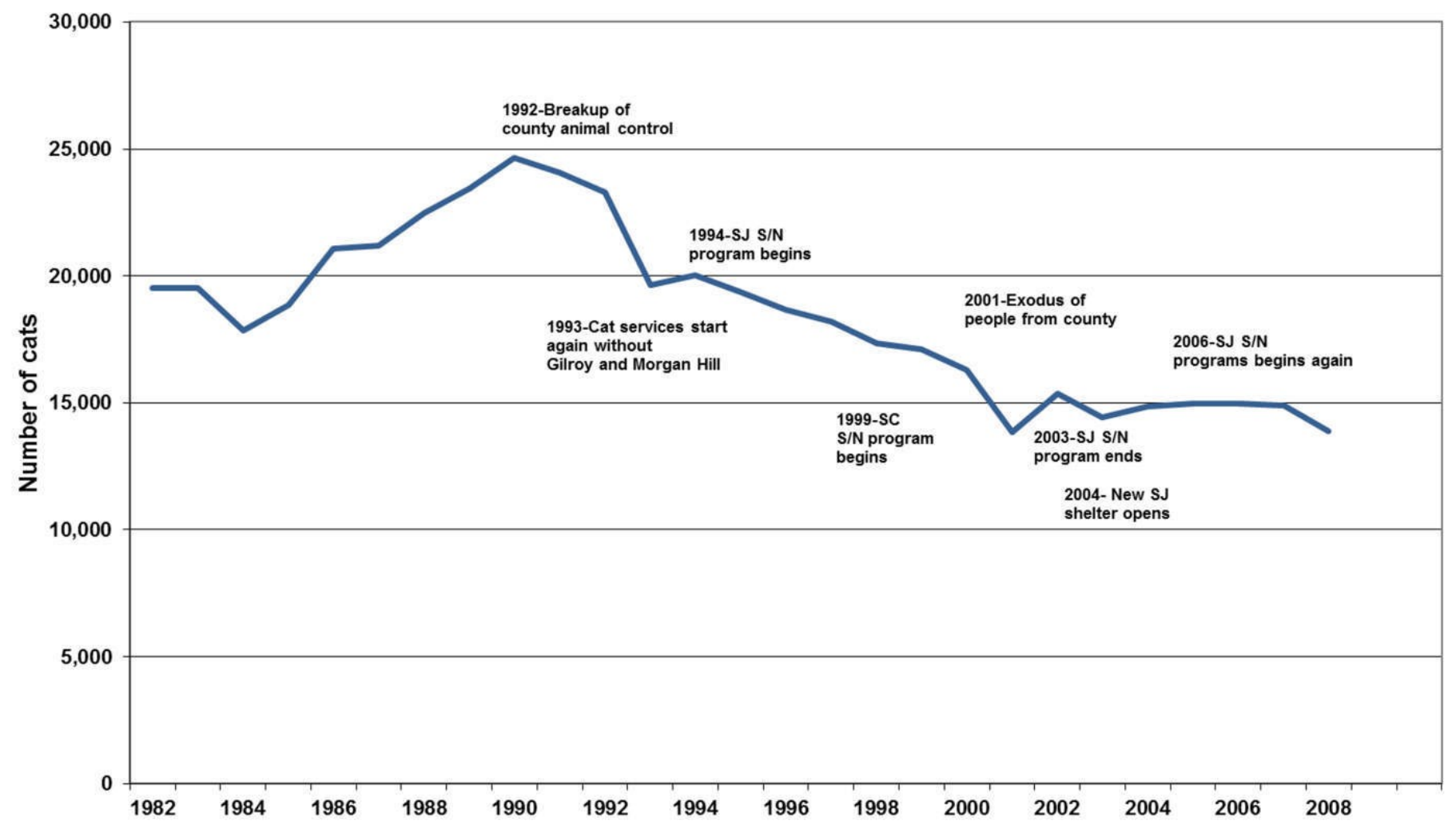




\section{Figure 4}

Regression analysis of intake of cats at shelters in Santa Clara ( $\mathrm{r}=0.98)$ and San Mateo Counties (r>0.99), 1990 - 2006.

Field services in Santa Clara County ended in 1992; at that time 60\% of cats were brought in through field services. Field services resumed in November 1993 in some cities.

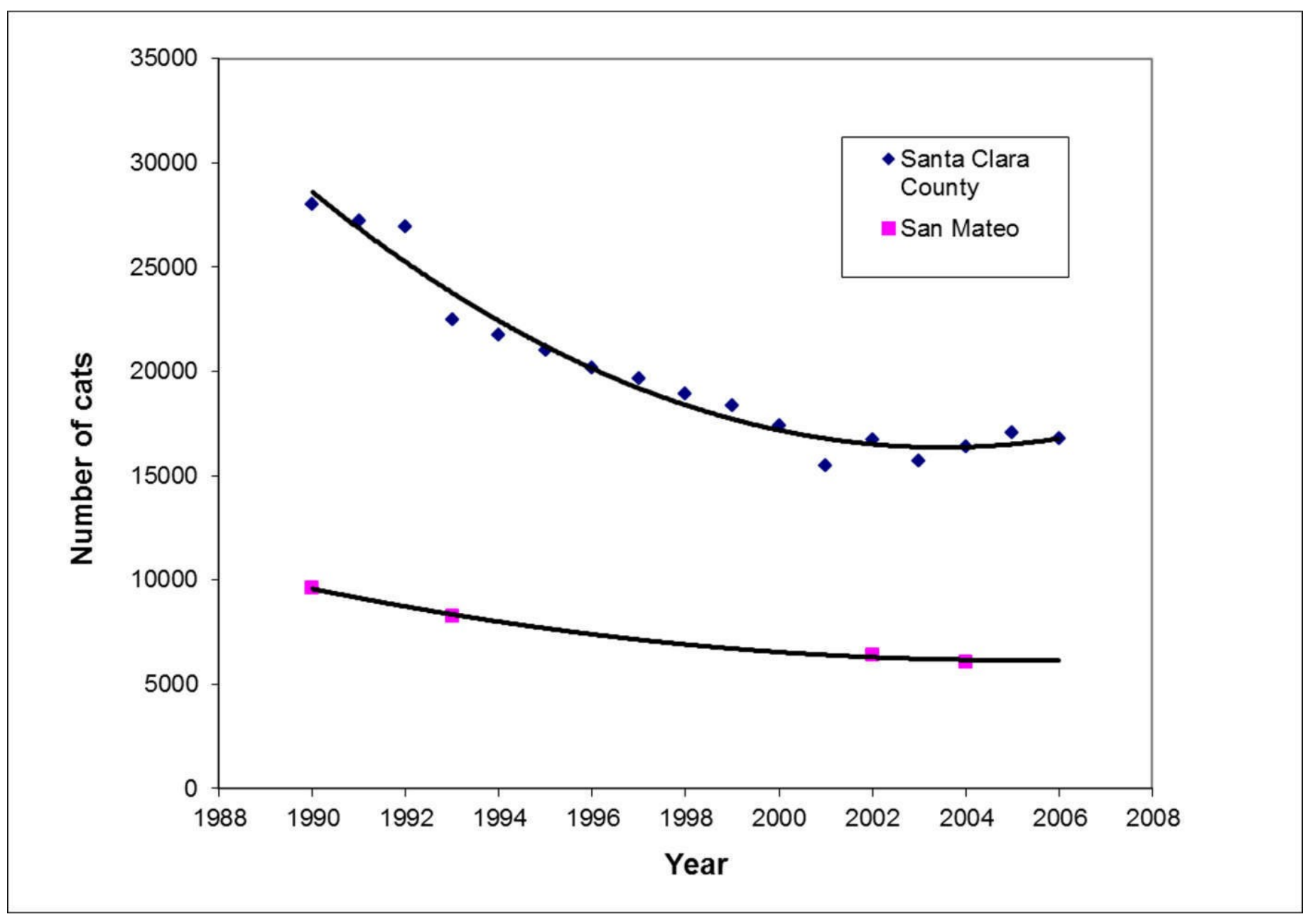




\section{Figure 5}

Observed numbers of cats surrendered to the shelters in Santa Clara County versus autoregressive integrated moving average (ARIMA) projected numbers of surrendered cats.

Figure uses the 1982-1993 data (before the launch of the spay/neuter voucher program) shelter data.

The lower (LCL) and upper (UCL) 95\% confidence limits of the ARIMA projection are also presented.

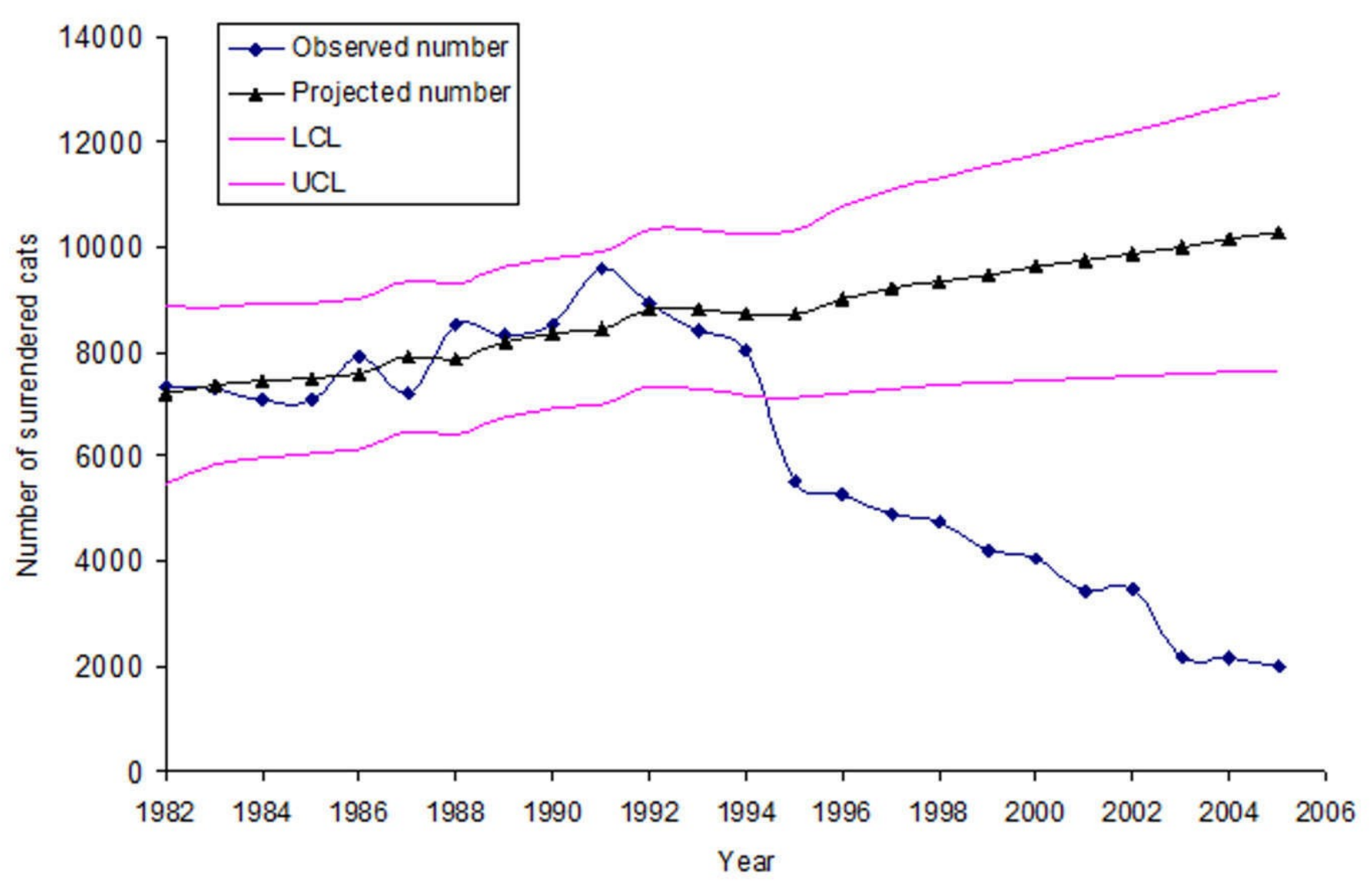




\section{Figure 6}

Observed numbers of cats brought to the shelters in Santa Clara County by the field service versus the autoregressive integrated moving average (ARIMA) projected numbers of cats.

Figure shows cats brought in by field service using the 1982-1993 (before the launch of the spay/neuter voucher program, shelter data). The lower (LCL) and upper (UCL) 95\% confidence limits of the ARIMA projection are also presented.

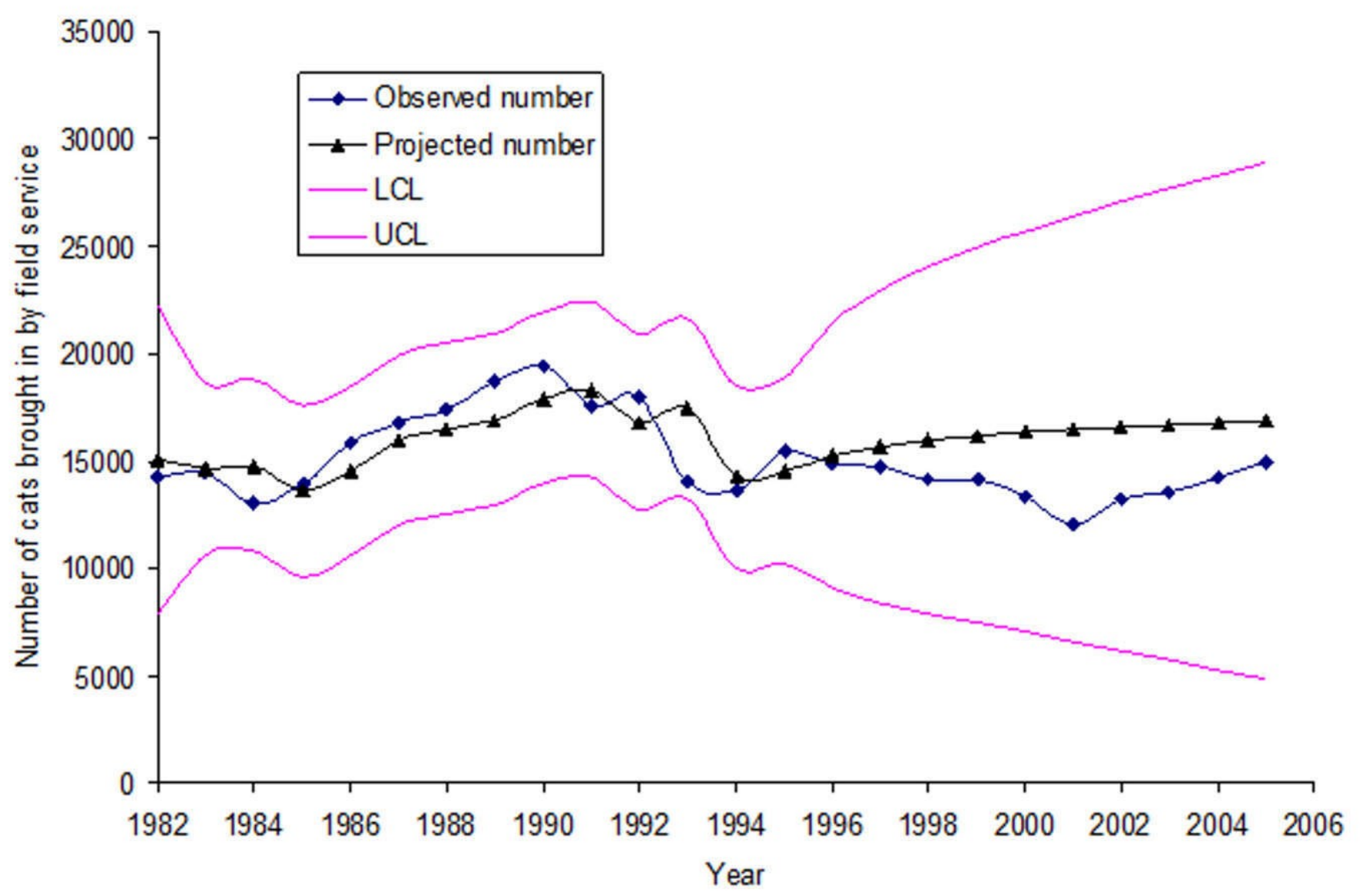

